\title{
How variable are hydroxyproline determinations made in different samples of the same liver?
}

\author{
Ana Thereza B. Gomes ${ }^{\mathrm{a}, \mathrm{c}, *}$, Carla Guimarães Bastos ${ }^{\mathrm{b}}$, Clara L. Afonso ${ }^{\mathrm{b}}$, \\ Bruno Frederico Medrado ${ }^{b}$, Zilton A. Andrade ${ }^{a}$ \\ ${ }^{a}$ Laboratory of Experimental Pathology, Gonçalo Moniz Research Center, FIOCRUZ, Rua Valdemar Falcão, n. 121 CEP 40295-001 Salvador, Bahia, Brazil \\ b Escola Bahiana de Medicina, Av. Dom João VI, 274 Brotas, Salvador, Bahia, Brazil \\ ${ }^{\mathrm{c}}$ Department of Internal Medicine, Faculty of Medicine, Federal University of Bahia, Salvador, Bahia, Brazil
}

Received 13 February 2006; received in revised form 1 May 2006; accepted 10 August 2006

Available online 18 August 2006

\begin{abstract}
Objectives: The haphazard distribution of fibrous tissue can interfere with quantitative methods for evaluating hepatic fibrosis. Inter-sample variation may represent a crucial issue when hydroxyproline measurement is used to quantify fibrosis. A comparative study of the hydroxyproline levels in normal and fibrotic rats is herein reported.

Material and methods: Twelve normal and 20 Capillaria hepatica-infected Wistar rats were used. Two fragments of the liver (A and B) of each rat were taken from separate areas and hydroxyproline measurements were made. Calculated differences in hydroxyproline measurements between samples from the same liver were analyzed by BOOTSTRAP.

Results: Differences in normal rats varied from 0.026 to $1.85 \mu \mathrm{mol}$ of $\mathrm{HP} / \mathrm{g}$, in ten rats, the difference was less than $0.50 \mu \mathrm{mol}$. In infected rats, it varied from 0.04 to $2.86 \mu \mathrm{mol} \mathrm{HP} / \mathrm{g}$. Differences higher than $0.69 \mu \mathrm{mol} / \mathrm{g}$ were significant for normal rats $(p<0.05)$ and above $1.22 \mu \mathrm{mol} / \mathrm{g}$ $(p<0.05)$ for fibrotic rats.

Conclusions: Hydroxyproline ratio in a normal liver kept a fair degree of reproducibility. In the presence of hepatic fibrosis, the levels of hydroxyproline may vary significantly between samples from a single liver and may have limited value in quantifying the extent of fibrosis.

(C) 2006 The Canadian Society of Clinical Chemists. All rights reserved.
\end{abstract}

Keywords: Hydroxyproline measurements; Reproducibility; Hepatic fibrosis; Capillaria hepatica; Inter-sample variation

\section{Introduction}

Fibrosis has been recognized as a key prognostic index for chronic hepatic disease progression $[1,2]$. Qualitative histological methods for evaluating fibrosis are to be regarded with caution since they are subjective [1] and may be misleading during the follow-up of patients [3]. Semi-quantitative methods improve the quality of histological evaluation, but even then the size of the biopsy material may be a limiting factor [2]. The methods also present reasonable intra- and inter-sample variation $[2,3]$.

\footnotetext{
* Corresponding author. Laboratory of Experimental Pathology, Gonçalo Moniz Research Center, FIOCRUZ, Rua Valdemar Falcão, n. 121 Brotas, CEP 40295-001 Salvador, Bahia, Brazil. Fax: +55 7131762155.

E-mail address: zilton@cpqgm.fiocruz.br (A.T.B. Gomes).
}

Quantitative methods are essential for evaluating fibrosis when more exact data are required, such as when one needs to ascertain the efficacy of treatment with new drugs or obtain sound prognostic data $[1,4]$. The haphazard distribution of fibrous tissue within the liver - in septa, bands and expanded portal spaces - can interfere with measurements regardless the method employed, be it qualitative, quantitative or semiquantitative $[1,3]$.

Hydroxyproline, an amino acid found almost exclusively in collagen, can be determined biochemically [5]. Measuring its concentration in the liver tissue is regarded as a good method to quantify fibrosis, especially during therapeutic trials with new potentially anti-fibrotic drugs [6-9,14,15,17]. In some investigations no reference is made as to the exact site from which samples were taken $[10,11]$. In others the fragments were occasionally taken from the same one site $[12,13]$. 
Considering a possible variation in fibrosis concentration between two samples from the same liver, one wonders how significant this could be. Since a thorough literature review did not reveal any information on this matter, and since it could have a bearing on current quantitative evaluation of hepatic fibrosis, a comparative study of the values of hydroxyproline measurements between two samples taken from the livers of normal and fibrotic (Capillaria hepatica-infected) rats was carried out and is herein reported.

\section{Materials and methods}

\section{Animals}

Thirty-two adult Wistar rats of both sexes, weighing initially approximately $150 \mathrm{~g}$ were used. They were maintained in wide metal boxes, in good light and temperature conditions, with free access to water and to a balanced pellet diet of commercially produced food for rats.

All procedures concerning animal experimentation were reviewed and approved by The Animal Care and Use Committee of our institution.

The animals were divided into two groups: (a) twelve normal intact rats; (b) twenty $C$. hepatica-infected rats. Infection was carried out with approximately 600 mature eggs of $C$. hepatica administered by gavage. Details on isolation, embryonation and counting of eggs appear elsewhere [16].

Thirty days following inoculation, animals of both groups were anesthetized and their livers removed. Animals were then sacrificed by severing their abdominal aorta. Two fragments of 150-200 mg were taken from separate areas of the livers and immediately kept in a $10 \%$ solution of formalin in distilled water until analysis.

\section{Hydroxyproline determination}

The hydroxyproline content in the two separate fragments (A and B) taken from each rat was measured using Stagemann's colorimetric method, as modified by Bergman and Loxley [18]. Briefly, the liver samples were hydrolyzed for $18 \mathrm{~h}$ in $5 \mathrm{~mL} 6 \mathrm{~N} \mathrm{HCl}$ at $110^{\circ} \mathrm{C}$, and then filtered. One drop of $1 \%$ phenolphthalein in absolute alcohol was added to $2 \mathrm{ml}$ of the filtrate as an indicator and neutralization was obtained with $10 \mathrm{~N} \mathrm{NaOH}$ and $3 \mathrm{~N} \mathrm{HCl}$. After neutralization subsequent steps were made in duplicate for each sample. To a $200 \mu \mathrm{L}$ of the above solution, $400 \mu \mathrm{L}$ of isopropanol in citrateacetate-buffered Chloramine $\mathrm{T}$ were added. After $4 \mathrm{~min}$, $2.5 \mathrm{~mL}$ of Ehrlich reagent was added. Tubes were wrapped in aluminum foil and incubated for $25 \mathrm{~min}$ in a water-bath at $60^{\circ} \mathrm{C}$.

Readings of the samples were made twice for each sample on the range of $558 \mathrm{~nm}$ absorbance band in a Hitachi spectrophotometer, mod. U-2000. Results were analyzed by computer and expressed as $\mu \mathrm{mol}$ hydroxyproline/g of hepatic tissue. The average from the two readings was used for the following analysis.

\section{Statistical analysis}

The mean, standard deviation and median from hydroxyproline measurements were considered. Calculated differences between hydroxyproline concentration in fragments A and B taken from each rat, both in normal and infected groups, were evaluated using a special method known as BOOTSTRAP. Differences between samples A and B from the same rat were considered as statistically significant when $p<0.05$.

\section{Results}

Comparative data from the samples taken from the same liver, both from normal and infected rats are depicted in Table 1, including the results of the hydroxyproline (HP) measurements. The weight of fragments $\mathrm{A}$ and $\mathrm{B}$ did not differ in either group of rats. Concentration of hydroxyproline was found to be higher in the infected animals when compared to that of the normal intact rats. Only one normal rat exhibited a hydroxyproline level of above $3.75 \mu \mathrm{mol} / \mathrm{g}$, and only one infected rat, presented a level of less than $3.5 \mu \mathrm{mol}$ of $\mathrm{HP} / \mathrm{g}$.

\section{Hydroxyproline analysis in normal rats}

The inter-sample values in normal rats are represented in Fig. 1. As can be seen the variation in hydroxyproline concentration between the fragments $\mathrm{A}$ and $\mathrm{B}$ was less than $0.50 \mu \mathrm{mol} / \mathrm{g}$ in ten rats. In only one healthy rat was the difference between the fragments A and B higher than $1.0 \mu \mathrm{mol} / \mathrm{g}$, reaching $1.85 \mu \mathrm{mol}$ of hydroxyproline/g of hepatic tissue.

\section{Hydroxyproline analysis in rats with liver fibrosis}

The hydroxyproline variation among fibrotic infected livers is shown in Fig. 2. Differences in concentrations of hydroxyproline between the fragments $\mathrm{A}$ and $\mathrm{B}$ varied from 0.04 to $2.86 \mu \mathrm{mol}$ of $\mathrm{HP} / \mathrm{g}$, the median reaching $0.71 \mu \mathrm{mol} / \mathrm{g}$. In five rats the difference was greater than $1.20 \mu \mathrm{mol} / \mathrm{g}$.

Table 1

General data of the hydroxyproline measurements

\begin{tabular}{llllll}
\hline & \multicolumn{2}{l}{ Normal rats } & & \multicolumn{2}{c}{ C. hepatica-infected RATS } \\
\cline { 2 - 3 } & $\begin{array}{l}\text { Fragment A } \\
(n=12)\end{array}$ & $\begin{array}{l}\text { Fragment B } \\
(n=12)\end{array}$ & & $\begin{array}{l}\text { Fragment A } \\
(n=20)\end{array}$ & $\begin{array}{l}\text { Fragment B } \\
(n=20)\end{array}$ \\
\hline Weight $^{\mathrm{a}}$ & $0.183 \pm 0.013$ & $0.187 \pm 0.007$ & & $0.183 \pm 0.011$ & $0.174 \pm 0.010$ \\
$\begin{array}{l}\text { Hydroxyproline } \\
(\mu \mathrm{mol} / \mathrm{g})\end{array}$ & & & & \\
$\quad$ Mean $\left( \pm \mathrm{SD}^{\mathrm{b}}\right)$ & $3.41 \pm 0.70$ & $3.29 \pm 0.31$ & & $5.34 \pm 0.91$ & $5.75 \pm 1.03$ \\
$\quad$ Median & 3.32 & 3.32 & & 5.47 & 5.64 \\
Maximum value & 5.40 & 3.77 & 6.48 & 7.66 \\
Minimum value & 2.53 & 2.88 & 3.40 & 3.90 \\
\hline
\end{tabular}

A comparison between two liver samples taken from different areas of a same liver (A and B), either from normal or Capillaria hepatica-infected rats.

${ }^{\text {a }}$ Mean \pm SD in grams.

${ }^{\mathrm{b}}$ Standard deviation. 


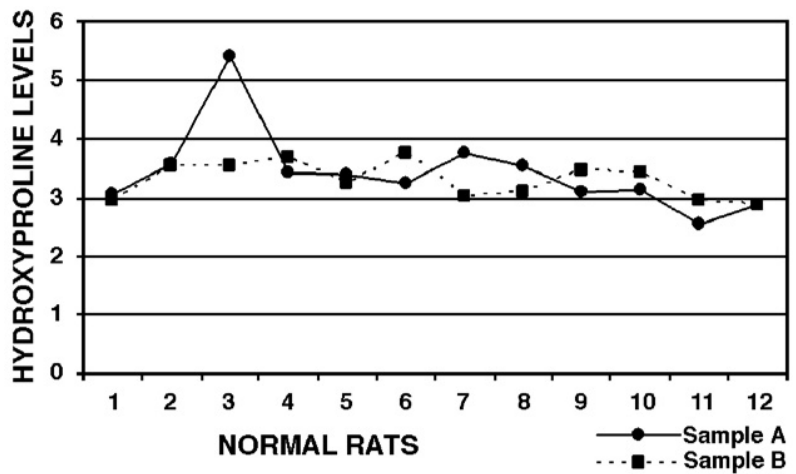

Fig. 1. Comparison of the variation in hydroxyproline contents ( $\mu \mathrm{mol} / \mathrm{g}$ hepatic tissue) between two liver tissue samples (A and B) taken from two areas apart of the same normal rat.

\section{Bootstrap analysis}

Results from differences between HP measurements obtained by means of the BOOTSTRAP method are shown in Table 2. The $p$ values are shown for differences in HP concentration between $0.15 \mu \mathrm{mol} / \mathrm{g}$ and $0.90 \mu \mathrm{mol} / \mathrm{g}$ in healthy rats. Thus, when the values of hydroxyproline levels were higher than $0.69 \mu \mathrm{mol} / \mathrm{g}$ between the samples A and B, they were considered significant $(p<0.05)$.

As for the infected rats with hepatic fibrosis the $p$ values are demonstrated for differences from $0.55 \mu \mathrm{mol} / \mathrm{g}$ to $1.60 \mu \mathrm{mol} / \mathrm{g}$. Differences between fragments A and B from a same rat were considered significant when higher than $1.22 \mu \mathrm{mol} / \mathrm{g}(p<0.05)$.

\section{Discussion}

The present study appears to be unique in its specific aim to investigate the reproducibility of hydroxyproline determinations when assessing hepatic fibrosis. There are many studies on hepatic fibrogenesis and fibrolysis and for some of them intersample variations of hydroxyproline measurements may represent a crucial issue even when other similar quantitative methods are being used.

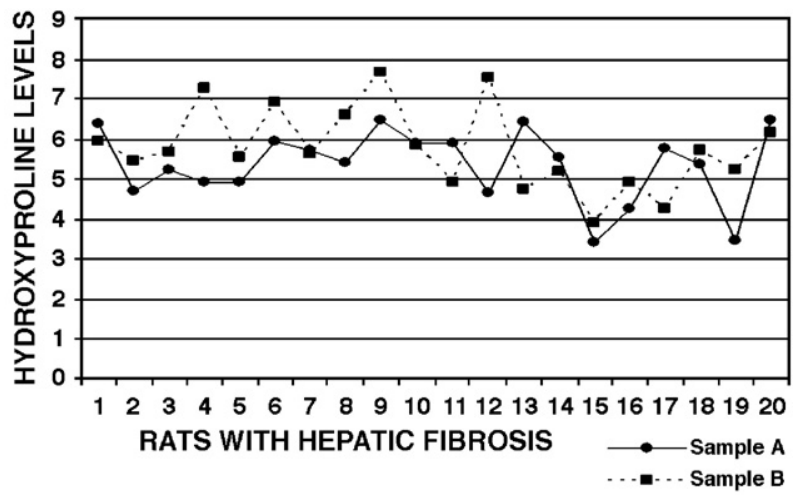

Fig. 2. Comparison of the variation in hydroxyproline content ( $\mu \mathrm{mol} / \mathrm{g}$ hepatic tissue) between two liver tissue samples (A and B) taken from two areas apart of the same Capillaria hepatica-infected rat (fibrotic rats).
Table 2

Critical values ${ }^{\text {a }}$ for differences of the hydroxyproline measurements between two fragments (A and B) taken from the same liver both from normal and $C$. hepatica-infected rats as analyzed by Bootstrap

\begin{tabular}{lllll}
\hline Normal rats & & & \multicolumn{2}{l}{ C. hepatica-infected rats } \\
\cline { 5 - 6 } Critical value & $p$ value & & Critical value & $p$ value \\
\hline 0.15 & 0.999 & & 0.55 & 0.999 \\
0.65 & 0.078 & & 1.20 & 0.067 \\
0.69 & 0.050 & 1.22 & 0.050 \\
0.90 & $0.004^{*}$ & 1.60 & $0.001 *$ \\
\hline
\end{tabular}

a Expressed as $\mu \mathrm{mol} / \mathrm{g}$ of liver.

* Statistically significant ( $p$ value $<0.05$ )

As expected, the present study revealed that hydroxyproline levels obtained were sufficient to discriminate a normal rat liver from one with hepatic fibrosis. Values above $4.0 \mu \mathrm{mol} / \mathrm{g}$ were a clear-cut indication of hepatic fibrosis.

Also, the present investigation revealed that measurements of hydroxyproline in samples from different areas of a normal liver tended to keep a fair degree of reproducibility. However, in one instance a difference of over $1.80 \mu \mathrm{mol}$ of $\mathrm{HP} / \mathrm{g}$ was registered. Probably this could be explained because one of the samples contained more portal spaces or larger ones, since the precaution was taken not to include areas near the capsule or in the proximities of the hilus.

The situation may be more complex with a diseased liver, especially if fibrosis, albeit diffuse, has areas of focal intensification. For the demonstration of this point we selected the case of $C$. hepatica-induced septal fibrosis of the liver in rats. This fibrosis regularly occurs in infected rats 25-28 days after inoculation [16]. Morphologically, it is similar to that seen in rats repeatedly treated with pig-serum [19]. However, in the rat capillariasis, besides diffuse septal fibrosis, there are scattered and focal parasitic inflammatory and fibrosis lesions around dead worms and their eggs, which are usually surrounded by a more or less thick fibrous capsule [16]. Obviously, such focal spots contain more fibrosis than elsewhere in the liver. The model seemed to be adequate to test the existence of variations between hydroxyproline concentrations in different samples of the same liver. Therefore variations between different samples were more frequent and significant in $C$. hepatica-infected livers than in normal livers. Differences among the fragments from a same liver greater than $1.22 \mu \mathrm{mol}$ of $\mathrm{HP} / \mathrm{g}$ were considered significant for infected livers. It is reasonable to speculate that these findings become particularly relevant when a correlation is made with a semiquantitative method that grades fibrosis as I (mild), II (moderate) and III (severe). Probably, in the present study, some samples taken from the same liver would be classified under different categories. More homogeneous results can be expected if more than one fragment, taken from different areas, is used.

In summary, it is important to be aware that the levels of hydroxyproline found using the colorimetric method may vary significantly between samples from a single diseased liver and therefore have limited value in quantifying the extent of fibrosis. In addition, our results suggest that further studies are 
required both to find out whether a single fragment would suffice if an adequate level of variation was previously known, as well as to carry out a blind comparison with a histological evaluation.

\section{Acknowledgments}

The authors thank Barbara Alves for her help with Capillaria hepatica infection in rats.

\section{References}

[1] Chevallier M, Guerret S, Chossegros P, Gerard F, Grimaud J-A. A histological semiquantitative scoring system for evaluation of hepatic fibrosis in needle liver biopsy specimens: comparison with morphometric studies. Hepatology 1994;20:349-55.

[2] Colloredo G, Guido M, Sonzogni A, Leandro G. Impact of liver biopsy size on histological evaluation of chronic viral hepatitis: the smaller the sample, the milder the disease. J Hepatol 2003;39:239-44.

[3] Regev A, Berho M, Jeffers LJ, Milikowski C, Molina EG, Pyrsopoulos NT, et al. Sampling error and intraobserver variation in liver biopsy in patients with chronic HCV infection. Am J Gastroenterol 2002;97: 2614-8.

[4] Baak JPA. The framework of pathology: good laboratory practice by quantitative and molecular methods. J Pathol 2002;198:277-83.

[5] Reedy GK, Enwemeka CS. A simplified method for the analysis of hydroxyproline in biological tissues. Clin Biochem 1996;29:325-9.

[6] Yoshiji H, Kuriyama S, Yoshii J, Ikenaka Y, Noguchi R, Nakatani T, et al. Tissue inhibitor of metalloproteinases -1 attenuates spontaneous liver fibrosis resolution in the transgenic mouse. Hepatology 2002;36:850-60

[7] Yuan G-J, Zhang M-L, Gong Z-J. Effects of PPARg agonist pioglitazone on rat hepatic fibrosis. World J Gastroenterol 2004;10(7):1047-51.
[8] Kusonose M, Qiu B, Cui T, Hamada A, Yoshioka S, Ono M, et al. Effect of Sho-saiko-to extract on hepatic inflammation and fibrosis in dimethylnitrosamine induced liver injury rats. Biol Pharm Bull 2002;25(11): $1417-21$

[9] Muriel P, Deheza R. Fibrosis and glycogen stores depletion induced by prolonged biliary obstruction in the rat are ameliorated by metadoxine. Liver 2003;23:262-8.

[10] Matsuda Y, Matsumoto K, Yamada A, et al. Preventive and therapeutic effects in rats of hepatocyte growth factor infusion on liver fibrosis/ cirrhosis. Hepatology 1997;26:81-9.

[11] Zhu J, Wu J, Frizell E, et al. Rapamycin inhibits hepatic stellate cell proliferation in vitro and limits fibrogenesis in an in vivo model of liver fibrosis. Gastroenterology 1999;117:1198-204.

[12] Muguerza B, Castilla-Cortázar I, García M, Quiroga J, Santidrián S, Prieto J. Antifibrogenic effect in vivo of low doses of insulin-like growth factor-I in cirrhotic rats. Biochim Biophys Acta 2001;1536:185-95.

[13] Jiang W, Yang CQ, Liu WB, Wang YQ, He BM, Wang JY. Blockage of transforming growth factor $\beta$ receptors prevents progression of pig seruminduced rat liver fibrosis. World J Gastroenterol 2004;10:1634-8.

[14] García L, Hernández I, Sandoval A, Salazar A, Garcia J, Vera J, et al. Pirfenidone effectively reverses experimental liver fibrosis. J Hepatol 2002;37:797-805.

[15] Ramos SG, Montenegro AP, Goissis G, Rossi MA. Captopril reduces collagen and mast cell and eosinophil accumulation in pig serum-induced rat liver fibrosis. Pathol Int 1994;44:655-61.

[16] Ferreira LA, Andrade ZA. Capillaria hepatica: a cause of septal fibrosis of the liver. Mem Inst Oswaldo Cruz 1993;88:441-7.

[17] Souza MM, Paraná R, Trepo C, Barbosa Jr AA, Oliveira I, Andrade ZA. Effect of interferon-á on experimental septal fibrosis of the liver-Study with a new model. Mem Inst Oswaldo Cruz 2001;96(3):343-8.

[18] Bergman A, Loxley R. Two improved and simplified method for the determination of hydroxyproline. Anal Chem 1963;35:1961-4.

[19] Paronetto F, Popper H. Chronic liver injury induced by immunologic reactions. Cirrhosis following immunization with heterologous sera. Am J Pathol 1966;40:1087-101. 